\title{
RETOS DE LA ACTUAL CULTURA CONTEMPORÁNEA A LAS INSTITUCIONES DE EDUCACIÓN PERSONALIZADA
}

\author{
Francisco Bobadilla Rodríguez \\ Universidad de Piura \\ francisco.bobadilla@udep.edu.pe
}

Fecha de recepción: mayo de 2019 Fecha de aceptación: diciembre de 2019

ReSUmen: Este ensayo es una propuesta para vitalizar a las instituciones educativas inspiradas en el modelo de educación personalizada. Se señalan dos grandes aspectos que configuran a la cultura contemporánea, el divertimento y el éxito. Ambas dimensiones no son suficientes para dar cabida a la plenitud de la persona humana. De ahí que se proponga llegar a una cultura del encuentro y a una cultura de la excelencia. El encuentro llama a la pedagogía del asombro que le otorga profundidad a la diversión y llama, asimismo, a la pedagogía de la promesa que le da duración al instante. De otro lado, el éxito llega a su plenitud con el afán de servicio desplegado en la pedagogía del empoderamiento y en la pedagogía del don.

Palabras clave: Promesa, asombro, éxito, servicio, empoderamiento, don.

* Francisco Bobadilla Rodríguez es abogado y Master en Derecho Civil por la Pontificia Universidad Católica del Perú. Doctor en Derecho por la Universidad de Zaragoza. Es profesor Ordinario Principal de la Universidad de Piura con 40 años de ejercicio docente, especializado en el aspecto antropológico, ético y jurídico de la conducta humana y experiencia en la conducción directiva de instituciones educativas. 


\section{CHALLENGES OF THE CURRENT CONTEMPORARY CULTURE TO INSTITUTIONS OF PERSONALIZED EDUCATION}

Abstract: This essay is a proposal to vitalize educational institutions inspired by the personalized education model. Two main aspects that make up contemporary culture are pointed out: amusement and success. Both dimensions are not sufficient to express the fullness of human person. Hence, it intends to reach a culture of encounter and a culture of excellence. The encounter recalls a pedagogy of awe that gives depth to amusement and also calls for the pedagogy of the promise which is what makes an instant last. On the other hand, success needs eagerness to serve and reaches its fullness with the pedagogy of empowerment and the pedagogy of gift.

KEYwORDs: promise, awe, success, service, empowerment, gift.

\section{Introducción}

T a sociedad contemporánea tiene unos rasgos que la caracterizan y es el humus en el que vivimos. Se nutre de paradigmas hondamente arraigados que generan patrones culturales expresados en las diversas dimensiones existenciales de la vida societaria: educación, arte, política, economía. Para efectos de la labor educativa que desplegamos en los colegios, resulta de vital importancia tener claro este ámbito cultural, a fin de adecuar la pedagogía visible y la educación invisible ${ }^{1}$ que procuramos ofrecer a nuestros alumnos, los jóvenes del siglo XXI.

1 "Grosso modo se podría pensar quela Pedagogía visible se manifiesta, predominantemente, 
Este ensayo es una propuesta en la que planteo la orientación que debe asumir la pedagogía de los colegios — cuyo ideario se basa en una educación personalizada ${ }^{2}$ de inspiración humanista y cristiana- en la sociedad en la que nos desenvolvemos. Con este propósito me fijo en dos rasgos estructurales de la cultura contemporánea: el instante y el afán de logro. El instante lleva a la cultura del divertimento ${ }^{3}$. El afán de logro configura la cultura del éxito.

Ambos modos de expresión de la cultura contemporánea plantean retos y problemas; a su vez, abren oportunidades a las instituciones educativas en su tarea de enseñar y formar a sus alumnos. Pienso que la propuesta de educación personalizada, situada en estas coordenadas culturales, ofrece una visión capaz de asumir los aportes de estas expresiones culturales y completarlas desde la visión humanista y cristiana del ser humano y de la sociedad.

Por tanto, la cultura del divertimento centrada en el pasatiempo y en el instante requiere de una cultura del encuentro que enfatice la duración ${ }^{4}$, dentro de la vida escolar, en la enseñanza sistemática y en el aprendizaje como adquisición de conocimientos, es decir, en los contenidos de la formación científica, mientras que la educación invisible, por profunda, se proyecta especialmente en la formación ética, es decir, en el desarrollo de aptitudes y promoción de valores y virtudes morales" (García Hoz, 1987, p. 27).

2 Estoy pensando en la propuesta de educación personalizada del maestro Víctor García Hoz que, desde muy temprano, esbozó una teoría educativa centrada en la persona en todas sus dimensiones. Cfr. GARCÍA HOZ, Víctor. Cuestiones de filosofía individual y social de la educación. Madrid, Rialp, 2da. Ed., 1962. La colección Tratado de la educación personalizada, dirigida por él y que agrupa a un gran número de especialistas, desarrolla ampliamente las diversas dimensiones del proceso educativo.

3 Divertimiento: De divertir

1. m. diversión (II acción de divertir).

2. m. diversión (II recreo, pasatiempo).

3. m. Distracción momentánea de la atención. (RAE)

4 El sociólogo Richard Sennet ha dedicado varios de sus libros a estudiar la inmediatez en el nuevo capitalismo flexible. Se pregunta: "¿Cómo decidimos lo que es valor duradero 
dimensión esencial para dotar de consistencia y sostenibilidad a la narrativa humana. De otro lado, la cultura del éxito tiene en su haber resaltar el afán de logro del homo faber, no obstante, se queda corta porque aún se puede ampliar el horizonte y elevar el listón del crecimiento humano. Esta tarea de esponjamiento queda mejor expresada en la cultura de la excelencia orientada a desarrollar la dimensión efusiva del homo sapiens. De este modo, la excelencia se constituye en la síntesis del afán de logro y la efusión, transfigurados en el afán de servicio.

La Cultura del encuentro se hace visible en la pedagogía del asombro y en la pedagogía de la promesa. La Cultura de la excelencia, por su parte, se apoya en una pedagogía del emprendimiento y en una pedagogía del don. En esta indagación solo señalaré las grandes líneas del derrotero que hemos de seguir.

\section{Cultura del Encuentro}

\subsection{Del divertimento al encuentro}

El divertimento, dice la Real Academia de la Lengua, es pasatiempo y distracción momentánea de la atención ${ }^{5}$. En este sentido, la cultura del divertimento recupera para el ser humano su dimensión lúdica. La en nosotros en una sociedad impaciente y centrada en lo inmediato? ¿Cómo perseguir metas a largo plazo en una economía entregada al corto plazo?” (2000, p, 10).

5 Vargas Llosa se ha referido a este efecto deficiente de la cultura contemporánea a la que ha denominado "la civilización del espectáculo" y lamenta que "convertir esa natural propensión a pasarlo bien en un valor supremo tiene consecuencias inesperadas: la banalización de la cultura, la generalización de la frivolidad y, en el campo de la información, que prolifere el periodismo irresponsable de la chismografía y el escándalo" (2012, p. 34). 
diversión se ha convertido en un protagonista de la vida personal. No es de extrañar, por eso, que la industria del ocio haya crecido tanto en las últimas décadas: cine, discotecas, bares, restaurantes. Cada vez nuevas emociones y experiencias hasta llegar, en muchos casos, al vértigo: velocidad, sensualidad, embriaguez, vanidad... El divertimento, así enfocado, se concentra en fomentar y satisfacer el deseo de bienes placenteros: comer, mirar, tocar, oír, gozar sensualmente. Bienes, desde luego, pero potenciados de tal modo que adormecen la dimensión espiritual del ser humano. La sensorialidad se refina al precio de opacar el crecimiento espiritual.

Se busca el divertimento, se organizan fiestas para pasarlo bien y encontrar la alegría. Sin embargo, se ha trivializado tanto el espíritu festivo que se le ha vaciado de su contenido natural: la alegría. Solo queda el ruido, el movimiento, la resaca y vuelta a empezar en un movimiento circular que suele acabar en el aburrimiento y la decepción ${ }^{6}$. Unas palabras de Benedicto XVI ante la Curia Romana nos pueden ayudar a salir de este callejón sin salida. Dijo: "la fiesta se puede organizar, la alegría no. Solo puede ofrecerse como don. (...) Es la expresión de le felicidad, del estar en armonía consigo mismo, algo que solo puede derivarse de estar en armonía con Dios y con su creación” (2008, párr. 32). La sola fiesta, pues, no garantiza la alegría, del mismo modo que moverse mucho y bailar hasta el agotamiento no son siempre expresión de felicidad $\mathrm{y}$, antes bien, podrían ser manifestación bulliciosa de la propia huida de uno mismo.

$6 \quad$ Lipovetsky llama a este estado de frustración sociedad de la decepción: "Cuanto más aumentan las exigencias de mayor bienestar y una vida mejor, más se ensanchan las arterias de la frustración. Los valores hedonistas, la superoferta, los ideales psicológicos los ríos de la información, todo esto ha dado lugar a un individuo más reflexivo, más exigente, pero también más propenso a sufrir decepciones. Después de las "culturas de la vergüenza” y de las "culturas de culpa”, como las que analizó Ruth Benedict, henos ahora en las culturas de la ansiedad, la frustración y el desengaño” (Lipovetsky, 2008, p. 21). 
La alegría no se organiza, tampoco se compra, es un regalo; no se alcanza, llega, adviene. Unas veces la alegría es chispeante, otras veces es quieta y serena, pero lo que pierde en brillo lo gana en peso. $\mathrm{Y}$ al igual que los peces necesitan del agua para vivir, así también la alegría surge allí en donde hay hombres y mujeres que día a día cultivan su vida, afirmando libremente su condición humana. La alegría limpia, transparente se destila gota a gota en el esfuerzo diario por hacer que la inteligencia, la voluntad y los afectos nos hagan alcanzar el mejor Juan evangelista que llevamos dentro. Es la armonía conmigo mismo.

Ahora bien, puestos a divertirnos — lo recuerda una vez más Benedicto XVI citando a Friedrich Nietzsche_- "la habilidad no está en organizar una fiesta, sino en traer a personas capaces de poner alegría”. Menuda tarea la de encontrar personas portadoras de un buen amor en el corazón. Cuando faltan los buenos amigos, lo que queda es el sustituto: más alcohol, más comida, más ruido. Los sentidos se embotan y el alma languidece, la depresión está servida. Las personas alegres, en cambio, saben pasarlo bien con dos soles en el bolsillo (una gaseosa, un chocolatito y poco más), sin necesidad de desparramar los sentidos y arruinarse económicamente el fin de semana. Una buena fiesta, entonces, se mide por la buena compañía y no hace falta estar, necesariamente, en la cubierta del Titanic. Es la armonía con la creación.

Recuperar la alegría de la diversión es, precisamente, uno de los aportes de la cultura del encuentro 7 . Dota a la cultura del divertimento de la alegría que se le escapa de las manos, pues la experiencia humana ha quedado

7 El profesor Gustavo Sánchez ha estudiado el sentido que tiene la cultura del encuentro en el pensamiento del Papa Francisco. Dice: "La cultura del encuentro supone el reconocimiento - en el sentido fuerte y completo de la expresión - del otro como persona, donde su valor está en ser distinto a mí, y por lo mismo, digno de acogida en el diálogo y en la escucha" (2018, p. 126). 
reducida a miradas de escaparate. Sin embargo, el aporte más importante de la cultura del encuentro es el descubrimiento del TÚ ${ }^{8}$. El compañero de trabajo en tanto que prójimo - mi prójimo en sentido estricto, pues es el más "próximo" en mi entorno habitual- me sale al encuentro, me interpela, me pregunta. Cuando entro en relación con el Tú adviene el encuentro interhumano, y se despliega el acontecer dialógico, cuyo movimiento principal es la orientación: todo mi ser abierto a la comprensión del ser que se pone frente a mí. Desde esta actitud, frente a mí no tengo solo al compañero, colega, vigilante, mozo, sino que descubro en aquella relación funcional el valor perenne de la dignidad humana. Es una actitud que trasciende lo efímero del momento y convierte el tropezón en un encuentro dialógico, produciéndose "una conversación que no es determinada por la necesidad de comunicar algo, ni de experimentar algo, ni de influir sobre alguien" (Buber, 1997, p. 42). Simplemente uno hacia el otro, abrazando en la particularidad del presente, la integridad de la persona. Alertas para no quedar fusionados en la anécdota, en la que también se revela el mismo prójimo en su persona.

Para encontrar el TÚ y la realidad en su profundidad y sencillez hemos de aprender a mirar contemplativamente, es decir, en el ver se enriquece el cariño. Todos entendemos que contemplar tiene un significado diferente al solo mirar. El que mira, simplemente observa, calibra, clasifica, califica, objetiva. Un ama de casa, por ejemplo, en el mercado mira una lechuga, la compara, se fija en la calidad. Puede mirar uno u otro producto y hace bien en hacerlo, porque escogerá el de mejor calidad, el de mejor precio. En fin, variables que son propias de ese tipo de observaciones. Pero,

8 Las referencias al YO-TÚ y YO-ELLO y el concepto de relaciones interpersonales son de Martin Buber (1998), filósofo dialógico de cuyos escritos, considero, se puede sacar mucho provecho para volver a personalizar las relaciones humanas. 
desde luego, no podemos decir lo mismo de esta señora cuando mira a su hijo pequeño. Al hijo pequeño no se le observa, no se le mira con esa frialdad, como quien va a comprar carne en el mercado. Al niño pequeño, cuando la mamá lo mira embobada, se le contempla. La mamá no lo calibra, no lo objetiviza, de la misma manera que no se mira con ternura a la lechuga o a la naranja.

Cuando afirmamos que una persona contempla a otra (o a un paisaje), estamos diciendo que toda la persona (y no solo su inteligencia) está mirando con gozo, recreándose en la actividad. Su mirada no es una mirada fría, es una mirada llena de afecto, de buena voluntad, de cariño. En este sentido, los enamorados se contemplan, es decir, se miran con cariño, cabeza y corazón por medio. No es una mirada que pasa de largo, es una mirada que se detiene porque aquella a quien contemplo me importa y mucho. Por eso, el que contempla conoce más y mejor, con más intensidad y con más profundidad. Llega a conocer esos detalles pequeños que pueden pasar desapercibidos a aquel que solo observa y que, por tanto, se queda en la superficie, lejano de la intimidad que no percibe.

Pero no solo el que contempla conoce más y mejor porque su mirada se vuelve más aguda, más profunda, más intensa, sino también porque la misma realidad (lo contemplado) se deja conocer, se entrega. Esto último se ve claramente en el trato con otras personas. Alguna vez nos ha pasado que nos encontramos con alguien a quien recién conocemos y empieza a preguntar demasiado, inquiriendo impúdica-mente en nuestra intimidad. Son preguntas que denotan, fundamentalmente, curiosidad frívola. Ante una situación así tendemos a protegernos, cerrando nuestra intimidad. Respondemos con evasivas o con falsas pistas. $\mathrm{Y}$ es que para comunicar la intimidad necesitamos calor, tiempo y ambiente adecuado. Y 
es lógico, dado que la intimidad es lo más propiamente nuestro y en donde nos sentimos más a gusto y no estamos dispuestos a revelarla a cualquier hijo de vecino, sin más.

En cambio, cuando nos encontramos frente a otra persona en la que inmediatamente notamos esa relación de empatía, porque vemos que efectivamente quiere nuestro bien, y nos quiere bien, es más fácil mostrarse tal cual somos. Mostramos aquello que llevamos en el alma y lo mostramos con la confianza de saber que aquella otra persona es un digno receptor de la intimidad que queremos comunicar. Y lo que pasa con las personas, pasa, asimismo con la creación toda: la realidad se abre a los ojos que miran con asombro.

La cultura del divertimento ha instalado el pasatiempo y la prisa $^{9}$. La cultura del encuentro aporta la alegría a la fiesta y nos enseña a mirar detenidamente la realidad para descubrir el TÚ y la belleza de la creación. La tarea que se nos presenta a los centros educativos es fomentar, transversalmente, aquellas expresiones humanas que llevan a detenerse en la realidad, que le ponen pausa al correr. Hemos de pensar creativamente en la generación de espacios de encuentro para ahondar en la propia intimidad

9 El papa Francisco habla de la sociedad desarraigada para referirse a la orfandad de vínculos sociales:

¿QUÉ ENTIENDE POR SOCIEDAD DESARRAIGADA?

Me refiero a una sociedad hecha de personas y de familias que poco a poco van perdiendo sus vínculos, ese tejido vital tan importante para sentirnos parte los unos de los otros, participes con los demás de un proyecto común, y común en el sentido más amplio de la palabra. Una sociedad está arraigada si es consciente de pertenecer a una historia y a otros, entendido esto en el significado más noble del término. Está, en cambio, desarraigada si el joven crece en una familia sin historia, sin memoria y, en consecuencia, sin raíces. Todos sabemos desde niños lo importante que son las raíces, incluso físicamente: si no hay raíces, cualquier viento acaba por arrastrarte. Por eso una de las primeras cosas en las que tenemos que pensar como padres, como familias, como pastores, es en los escenarios donde arraigar, donde generar vínculos, donde hacer crecer esa red vital que nos permita sentirnos en casa (2018, pp. 34-35). 
y en el conocimiento cercano del ser de las cosas. Aprender, nuevamente a mirar, pausada y sosegadamente. Sin esa mirada honda no hay admiración. Perdemos la esencia de las cosas y apenas rozamos la superficie de la realidad. Para educar esta capacidad de admiración hemos de trabajar en una pedagogía del asombro, es decir, diseñar unos modos pedagógicos que ayuden al alumno a fomentar la vida interior, a cultivar el espíritu y a detenerse en las realidades que se abren en ámbitos de intimidad.

\subsection{Pedagogía del asombro ${ }^{10}$}

El asombro es la capacidad humana que mirar a la realidad con admiración. Es una mirada intelectual y afectiva a la vez. No es el simple observar de modo objetivo a las cosas, sino que se trata de una mirada contemplativa, por tanto, respetuosa de la realidad, en un intento de acceder amorosamente a su conocimiento. La mirada contemplativa respeta lo mirado. Afirma la realidad, la acoge. Se opone a la prisa, a la manipulación.

\subsubsection{Vida interior, silencio y soledad ${ }^{11}$}

Es un tópico común, casi pacíficamente admitido por propios y extraños, que el cambio y el aprendizaje continuos son signos de nuestro tiempo. En las organizaciones se nos pide ser proactivos, tener mucha iniciativa, innovar, movernos de aquí para allá. De hecho, rehuimos la quietud y queremos ocuparnos en hacer cosas. Hay días que son de vértigo,

10 Tomo el concepto asombro de San Juan Pablo II. Es el concepto con el que denomina la admiración de los clásicos, en tanto inicio de la filosofía. Su poemario Tríptico Romano (2003) comienza, precisamente, con un precioso poema titulado ASOMBRO. En mi ensayo "Poesía y antropología en Tríptico Romano" (Velezmoro (ed.), 2010, pp. 59-72) desarrollo la idea de asombro en San Juan Pablo II. De otro lado, para revisar el concepto de admiración como comienzo de la filosofía, puede verse: Polo (1995, pp. 15-20).

11 Véase Sarah (2016). Es un libro sugerente, un viaje al fondo del alma en clave católica. 
repletos de actividades que simplemente nos arrastran. Vivimos en una sociedad que nos vuelca hacia fuera hasta el agotamiento, al punto que cuando llega el reposo no sabemos qué hacer con él. Hemos perdido la capacidad de vivir con nosotros mismos, incompetencia vital que salta a la vista en la cada vez más frecuente crisis existencial de los domingos por la tarde. No está en juego solo unas horas de la semana, está en juego la existencia misma. ¿No será que, de tanto hacer, nos hemos olvidado de vivir? ¿No será que el buen vivir no se satura con el solo hacer por mucho que hagamos? Una vida con pocos argumentos vitales está expuesta de modo más frecuente a estas crisis de desgana y aburrimiento.

Vacío existencial que delata carencia de vida interior y explica en parte el miedo al silencio y a la soledad; asimismo, pone en evidencia la urgencia de reconciliarnos con nosotros mismos, de hacer un parón en la alocada carrera del día a día para esperar a nuestra alma que ha quedado rezagada en algún recodo del camino. Silencio y soledad que se traducen en tiempo interior para reflexionar y meditar, para decirnos esas cosas que no podemos gritar en voz alta. Espacios de reflexión para volver a preguntarnos quién soy, adónde voy, qué estoy haciendo de mi vida. Espacios de recogimiento interior para acertar en la conducción de nuestro proyecto de vida, a fin de no defraudar la vocación personal. Una vida así, que no renuncia a ser una vida personal no está exenta de sorpresas, pues, así como puede encontrarse riqueza interior, también cabe el susto cuando se halla opacidad y pobreza existencial: heridas del alma mal curadas o interioridad diminuta y frívola. Ambas situaciones reclaman que aclare y ordene mi vida.

Quien cultiva su vida interior no se pierde en el anonimato grupal o masivo del "se dice", "se hace", "se escucha", "se viste", "se lleva”, sino que vive en primera persona sus relaciones con los otros: la amistad y el amor 
son las dimensiones naturales a las que se abre su ser. Un corazón así no se aquieta en la superficialidad bulliciosa de la cháchara festiva ni el vértigo de las montañas rusas de feria, pide más y por eso busca el encuentro limpio y perdurable. Allí donde la palabra revela el Tú y el silencio se convierte en guardián que custodia con recato el misterio — que no el simple secretode la biografía personal del amigo o de la amada. La vida interior es vida hacia adentro. Es crecimiento espiritual. Es capacidad de acoger en el alma y en el corazón las dimensiones más profundas de las cosas. Buscamos las cosas de arriba y las cosas del alma. No es actitud pasiva, por el contrario, supone un continuo movimiento hacia dentro, hacia el fondo del alma en busca de la propia intimidad.

Saber hacer amigos, sí; pero sobre todo saber vivir la amistad. Cuando no nos hemos dado tiempo para guardar cosas en el corazón, la conversación se torna insulsa y se tiñe de tonos sensuales que delatan la precariedad existencial. Solo queda la agitación, de ahí que el fin de semana, en muchos casos, empiece con aguacero y termine en un diluvio de cerveza - vasos, jarras, yardas - y, como dice la canción, en un ambiente así "a la noche se le fue la mano". No tengo nada contra las noches ni contra las bebidas espirituosas, más aún, soy muy partidario de las fiestas y en buena hora que las haya. Afirmo que hay que saber dar con la medida ya que, de ordinario, un corazón macerado en alcohol, difícilmente acoge y guarda las confidencias del amigo hechas con la voz bajita del alma.

La cultura del espectáculo tiene horror al silencio y a la soledad. Los espacios en blanco, los tiempos muertos desesperan a quien está acostumbrado a correr y a hacer. Hay horror al vacío. Es necesario enseñar a estar solo frente a un libro. Es necesario enseñar el recogimiento, es decir, 
la capacidad del ser humano de recoger las velas del alma; cuerpo, alma y espíritu vuelven a conversar entre sí. Cesa el ruido y viene el reposo.

La vida interior, pues, requiere del silencio que no es ocioso ni mudo, es elocuente. Gracias a él se remansan ideas y experiencias. Silencio que lleva al recogimiento y abre las puertas a la confesión, al arrepentimiento, al gozo interior, a la contemplación, a la conversión. Al cabo de los años, la buena vida o la vida fallida dejan surcos en el alma y en el cuerpo. Como dice Susanna Tamaro: "entre la vida del justo y la del impío, ¿cuál hemos escogido? ¿Habla nuestra mirada de la plenitud del corazón o son solo nuestros labios los que lo hacen? ¿Hay un fuego que arde ahí dentro o es solo una lámpara para broncear?”. Preguntas inquietantes, pero, a la vez animantes y nos recuerdan que la vida no solo hay que vivirla hacia fuera, sino también hacia dentro: la calidad de la vida interior es lo que distingue la valía personal de unos y otros. Después de todo, al final de nuestros días, no se nos juzgará de lo mucho que hemos hecho, sino de cuánto y cómo hemos amado.

\subsubsection{Sentido ${ }^{12}$}

En más de una oportunidad nos hemos topado con hechos o dichos a los que no les encontramos lógica, pues escapan a una secuencia racional y decimos “esto no tiene sentido". Esta experiencia es, quizá, la más cercana a la idea de lo que solemos entender como "el sentido de la vida", es decir una

12 Cuando me refiero al sentido sigo la orientación que articula la propuesta de Víktor Frankl (2015) y su teoría de la logoterapia. Entre los autores contemporáneos, me inclino por Grondin (2014). Este último autor hace un repaso — desde la hermenéutica- de los asuntos esenciales de la vida. Es una propuesta equilibrada, ponderada y con sentido trascendente de la existencia. 
biografía personal con dirección, rumbo, en la que cada tramo existencial nos da peso específico.

"Arrieros somos y en el camino nos encontramos" dice el refrán popular. Caminar es, ciertamente, uno de los rasgos que más nos definen como seres humanos. Sin embargo, una vida con sentido no es solo un caminar sobre senderos trazados o por hacer. Importa, desde luego, el hacia dónde vamos; pero es, igualmente esencial, lo que queda atrás como saldo. Y ese saldo se mide por lo que pesa, más que por lo que luce. Un peso que le otorga consistencia a la vida en un tramado de logros y fracasos, alegrías y penas. Poco aportan a este propósito, las risas huecas, las horas locas, los vértigos existenciales. Con estas últimas experiencias se flota, se olvida, se vive el instante; su saldo es el vacío.

El sentido de la vida articula pasado, presente y futuro; su fruto es la serenidad y combina muy bien con el oro viejo, nada llamativo y siempre valioso. Combina, asimismo, más con una actitud humilde de búsqueda que con la actitud altanera del genio de la lámpara de Aladino que todo lo puede. Encontrar el sentido de la vida se parece mucho a jugar a "las escondidas": cierra los ojos y, al cabo de un corto tiempo, busca. En tanto que búsqueda supone un cierto desasosiego, una incomodidad con el presente y desorientación respecto del futuro, mas no es búsqueda sin término. El "ampay" llega, te encontré. Ya tengo un "qué" en las manos y la vida se va coloreando. Paso a paso el paisaje se llena de formas, tonalidades, perspectivas; un toque aquí, otro allá. Llega el cansancio, se descansa y vuelta a tomar el pincel. Con san Juan Pablo II, en su Tríptico Romano, podemos decir que los días del ser humano, tantas veces rutinarios, "tienen sentido, tienen sentido", aun en sus tardes más grises y en sus tardes más oscuras. Un riachuelo corre, pero no sabe que corre. 
Una vida sin sentido, lo sabemos, es una vida vacía cuyo telón de fondo puede ser el fracaso existencial. Vivimos en una sociedad que nos hace correr de un sitio a otro. No hay tiempo para el reposo, todo pasa muy rápido cual película de acción en la que no hace falta pensar nada. Un ambiente así, no se presta para asumir la conducción consistente de nuestra vida: ¡calma, alma! Y dado que encontrar el sentido de la propia existencia es un asunto serio, démonos tiempo para buscar nuestra misión en la vida. Búsqueda serena, sin inventarnos angustias gratuitas y sabiendo que la vida es para vivirla, es decir, tampoco nos pasemos los días y meses rizando el rizo. Después de todo es condición de vida, como lo dice San Pablo, "ver ahora como en espejo, borrosamente". Así que, a caminar, pues cada paso nos desvela el sentido de la vida.

\subsubsection{Relaciones interpersonales ${ }^{13}$}

Generamos infinidad de relaciones funcionales, es decir relaciones mediales que se caracterizan por un intercambio de cosas o de servicios. En el trabajo nos relacionamos con los colegas funcionalmente. En la calle o cuando acudimos a un establecimiento comercial, seguimos estableciendo relaciones funcionales. El corazón humano no se aquieta con las relaciones mediales o meramente funcionales: hago para que hagas, doy para que des. Tenemos nostalgia de lo íntimo y cercano, descansamos en lo interpersonal, de ahí que haga falta el aprendizaje de estas relaciones y de la comunicación interpersonal que se sigue de ellas.

13 Siguiendo a Martin Buber, desarrollo este tema en González Umeres (2009, pp. 33-44). 


\subsubsection{La verdad como encuentro ${ }^{14}$}

La verdad es adecuación del pensamiento a la realidad y, también, se le puede entender como encuentro, es decir, el descubrimiento de la verdad que deslumbra y convoca. Este deslumbramiento que nos hace ver el propósito de la vida, se convierte en el elemento configurante de la misión personal. La verdad de la vida se nos muestra y se constituye en el aliciente de la biografía personal.

En el encuentro nos reconciliamos con la realidad. El pasatiempo recupera su rostro de belleza que ayuda a encontrar la bondad de la creación y nos permite conocer la verdad que anida en ella. Volvemos a encontrarnos con el ser de las cosas.

\subsubsection{Ambitos ${ }^{15}$ para la pedagogía del asombro}

Decíamos que la tarea pendiente es enseñar a mirar y la experiencia de la belleza es, sin lugar a dudas, el camino más adecuado en estos tiempos

14 "La verdad como encuentro" es una expresión que tomo de Leonardo Polo. Se puede revisar: Polo (1996, pp. 197-206) y (2006, pp. 162-164).

15 Tomo el concepto ámbito en el sentido desarrollado ampliamente por Alfonso López Quintás, quien distingue entre objetos, ámbitos y sujetos como distintos modos de la realidad. Dice: "a las realidades que no están hechas de una vez por todas, sino que tienen iniciativa y deben ir configurando su ser mediante la creación de vínculos fecundos con las realidades del entorno las denomino 'ámbitos de realidad' o, sencillamente, ámbitos" (1999, p. 34). Una persona tiene capacidad de ser ámbito, una cosa, también. López Quintás ha desarrollado esta idea en la literatura, la música y el cine.

16 El discurso de referencia puede encontrarse en Solzhenitsyn (1978, pp. 7-27). 
ser a través de la belleza. Desde este trascendental del ser, se llegaba a la bondad de las cosas, a su verdad y a la hondura de la realidad. Desde la perspectiva clásica del pensamiento, la propuesta del premio Nobel es volver a poner los fundamentos en los trascendentales metafísicos de la realidad: esse, verum, bonum, pulchrum, convertuntur. En esta misma línea se mueve la propuesta evangelizadora del obispo auxiliar de Los Ángeles quien muestra la belleza de la fe y, paso a paso, presenta la centralidad de la persona de Cristo, Dios encarnado ${ }^{17}$. Se trata, pues, de jalar desde la belleza hasta llegar al ser, pasando por la bondad y la verdad de realidad.
a) La literatura ${ }^{18}$
b) La música
c) El cine
d) El arte: pintura, escultura ${ }^{19}$

17 "Barron está absolutamente convencido de que la fe católica es verdadera y buena; pero también lo está de que es atractiva, divertida, plena y vital y, si consigue que la gente atraviese el ruido de fondo de la cultura, responderán a ella” (Barron 2018, p. 50). En este mismo sentido se mueve Barrón (2017).

18 Un libro magistral para el profesor y el amante de las letras es el de Moeller (2008). En esencia, la caracterización que realiza frente a la precariedad de lo humano por parte del pensamiento helénico y el cristiano es muy esclarecedora. Los griegos consideran que cuando el hombre falla es por debilidad, serían los dioses quienes introducen el mal en las acciones de los hombres. En cambio, la concepción cristiana, considera que, además de la fragilidad, el hombre también obra torcidamente por malicia. Desde luego, la monumental obra de Moeller, en seis tomos, de su Literatura del siglo XX y cristianismo es un recorrido honesto y lúcido de los principales autores del siglo pasado.

19 Véase Han (2016). El autor, agudo observador de la cultura contemporánea hace una crítica a la reducción del sentido de la belleza en nuestro tiempo. Dice: "Lo bello promete libertad y reconciliación. En presencia de lo bello desaparecen los anhelos y los imperativos. Así es como hace posible una relación libre con el mundo y consigo mismo. La estética hegeliana de lo bello se opone diametralmente al régimen estético actual" (p.82). En cambio, continúa afirmando Han, "La calocracia neoliberal genera imperativos. El bótox, la bulimia y las operaciones estéticas reflejan su terror. Lo bello, sobre todo, tiene que suscitar estímulos y captar la atención. Incluso el arte, que para Hegel es inalienable, hoy se somete por completo a la lógica del capital. La libertad del 
e) Paseos (campo, museos, parques, malecones)

\subsubsection{El retorno a la realidad}

La realidad, las cosas, las personas, los problemas están allí. A veces, uno mismo forma parte de esa realidad o problema, y si lo que deseamos tener es un buen conocimiento, ganaremos más si logramos ajustar nuestro pensamiento a las cosas y no al revés. Pues bien, en el esfuerzo por conocer y conocernos es de buen gusto no apartarse del sentido común, que la Real Academia de la Lengua define como "la facultad, que la generalidad de las personas tiene, de juzgar razonablemente de las cosas".

Un buen conocimiento que no sea solo gimnasia o malabarismo intelectual, ha de ser continuidad del sentido común, ha de permanecer fiel a la experiencia. La realidad no hay que inventarla, basta con descubrirla, del mismo modo que las “oportunidades” no se inventan, están allí. Sentido común es pues, sentido de la realidad. Es claridad que nos permite llamar a las cosas por su nombre, con la sencillez de aquel niño del cuento que grita a todo pulmón que el Rey está desnudo. Para no perdernos en excesivas teorías - que las hay para todos los gustos - es muy conveniente colocar buenas dosis de sentido común en nuestros juicios, para llamar a las cosas por su nombre.

Urge recuperar la verdad de las palabras en el diálogo. La sola retórica o verborrea, carente de realidades, es ineficaz, cansa y aburre. Asusta escuchar el uso abusivo que se hace del lenguaje y el descaro con que se encubren las realidades a base de torcer el significado de las palabras y sus conceptos. No está de más recordar la definición lógica de la palabra: "voz

arte se subordina a la libertad del capital" (p. 82). Según Han, ya no solo se trata de que la belleza salve al mundo como lo quería Fiódor Dostoyevski, sino que, incluso, es necesario salvar a la belleza de la banalización a la que está expuesta en la sociedad actual. 
convencional significativa de un concepto, que a su vez es semejanza de la cosa". A su vez, el concepto es la "representación de la esencia de algo, es decir, significa aquello que la cosa es", es decir, significa principalmente la cosa (res), la realidad. Por eso, cuando lo que digo corresponde con la realidad, se dice que hay verdad y, al revés, si lo que digo no corresponde con la realidad, entonces eso es falso. Y hay quienes no se han enterado y pareciera que intentan convencernos de que lo que está equivocado es la realidad y no lo que dice. Intento por demás inútil y condenado al fracaso hasta el punto de echar sombras sobre la credibilidad del emisor.

Sí, el sentido común no ha sido derogado y hay que hacer uso de él para hacernos cargo de las múltiples situaciones que hemos de juzgar o sobre las que hay que tomar decisiones. No hay que renunciar al conocimiento espontáneo de las cosas, no sistematizado, pero igualmente verdadero como lo es el conocimiento científico, aunque no tan elaborado como este. Y es más necesario aún en los asuntos humanos, cuyo conocimiento no es patrimonio de los especialistas, sino que es sabiduría común, intuición, olfato para darse cuenta cuando algo va bien o va camino a la amargura... Es decir, aun cuando existe un legítimo conocimiento profundo y científico del ser humano, está claro que, para ir por la vida con un mínimo de acierto, no es condición necesaria que todos los mortales seamos sicólogos, filósofos, antropólogos, sociólogos, educadores y un largo etcétera. Si para acertar en las cosas de la vida hiciera falta un equipaje cognoscitivo de esta naturaleza, estamos perdidos. Afortunadamente, no es así.

Son los nuestros tiempos de alta conectividad, pero no, necesariamente, de comunicación profunda. La llamada realidad virtual no es suficiente y no sustituye al encuentro con la realidad en todas sus 
dimensiones. Tenemos una bonita y retadora tarea que podría sintetizarse en estos tres pasos:
a) Pasar de lo virtual a lo real.
b) Pasar de la llama a la brasa.
c) Pasar de la superficie a la raíz.

\subsection{Pedagogía de la promesa}

Vivimos en una cultura de lo efímero, del instante, del descarte. De lo efímero, en tanto que los bienes y los servicios desaparecen en la sola mirada o en el consumo. Del instante, en tanto que todo se resuelve en el momento. El instante llama a otro instante y cada vez más novedoso. No hay continuidad, hay solo coincidencia, suma mecánica de instantes. El instante está incapacitado para engendrar, para hacer costumbres o para hacer ritos. Cultura del descarte porque usa y arroja lo inservible y porque centra las relaciones, no en el YO-TÚ, sino en el YO-ELLO. El prójimo se convierte en ello, en una cosa o en un servicio que se utiliza y, cuando deja de ser útil, se descarta.

Es la cultura del YO inflamado y de la cultura del consumo. Genera seres humanos incapaces de honrar su palabra en el tiempo. Su voluntad es frágil ante el compromiso ${ }^{20}$. No tienen historia, viven en presente; su ilusión está en la consecución de nuevos placeres efímeros que en algo satisfagan

20 La sociología contemporánea llama la atención de la falta de vínculos propio del capitalismo flexible como lo llama Richard Sennet: "¿Cómo decidimos lo que es de valor duradero en nosotros en una sociedad impaciente y centrada en lo inmediato? ¿Cómo perseguir metas a largo plazo en una economía entregada al corto plazo? ¿Cómo sostener la lealtad y el compromiso recíproco en instituciones que están en continua desintegración o reorganización? Éstas son las cuestiones relativas al carácter que plantea el nuevo capitalismo flexible" (2000, p. 10). 
el deseo. La cultura de lo efímero, llama urgentemente, a la conveniencia de fortalecer la capacidad humana de prometer. Se trata de recuperar la capacidad del ser humano de prometer libremente, de comprometerse en proyectos de mediano y largo plazo; incluso en proyectos que involucren toda la vida como puede ser el matrimonio o el celibato apostólico. En la cultura contemporánea la promesa es frágil y cortoplacista ${ }^{21}$. Las rupturas de los vínculos asumidos se convierten en una epidemia. Se trata de generar comunidades de práctica que ayuden a nuestros alumnos a sostener sus promesas en el tiempo. Claramente la cultura de la promesa es una cultura contracorriente.

Dice Chesterton que prometer es acordar "una cita consigo mismo en algún lugar o fecha lejanos. El peligro está en que no acudamos a la cita". Nicola Di Bari en una de sus canciones le dice a su amada "Verás, yo volverél Te lo prometo volverél ¡Te lo juro amor, volveré...!/ porque te amo, ¡Te amo...!" La promesa estaba hecha, no sé si el desgarrado enamorado regresó en busca de su amada. Sí nos consta que el renombrado J. R. Tolkien, al cumplir los 21 años fue al encuentro de Edith, su futura esposa. Su tutor le había prohibido que la viera mientras estuviese estudiando en la Universidad. Cumplió ambas promesas, a su tutor y a su novia.

La cultura contemporánea no favorece la capacidad de prometer y menos la de hacer promesas de largo plazo o de toda la vida. Podemos cambiar de productos y de marcas con mucha facilidad. Moverse de un trabajo a otro es relativamente fácil, sobre todo cuando se es joven y competitivo. La cultura del éxito, fomentada en bastantes ámbitos educativos, lleva a formar jóvenes que desean llegar cuanto antes a buenos puestos y mejores salarios. La virtud de la paciencia es la menos fomentada. Todo se quiere para

21 En mi artículo "El emotivismo libertario y sus secuelas" (Bobadilla, 2014, pp. 127-150) desarrollo las características de la promesa en la actual sociedad liberal. 
ahorita. Un ambiente así deteriora la capacidad de compromiso: a la menor molestia, se rompe la promesa y no se está dispuesto a resistir e insistir.

No le falta razón a Chesterton cuando señala que en nuestro tiempo hay un cierto "terror a uno mismo, a la debilidad y mutabilidad propias".

Un hombre moderno — continúa diciendo- se abstiene de jurar que contará las hojas de uno de cada tres árboles que encuentre en, no porque hacerlo sea estúpido, sino porque posee la profunda convicción de que, antes de haber llegado a la hoja número trescientos veintinueve del primer árbol, estará demasiado cansado del asunto y querrá volver a casa para tomar el té. (2012, p. 64)

Dicho de otro modo, podemos anidar en nuestro interior el temor de que, llegada la luna llena, nos convirtamos en otra persona distinta del que hizo la promesa. Las dudas nos asaltan: ¿y si en lugar de Julieta, más adelante aparece Beatriz? ¿Por qué mantener la obligación de venderle a Juan según contrato firmado, si puedo vender mi mercancía a Pedro, a mejor precio? ¿Por qué comprometerme a acudir a la cita, si ya no tengo ganas o me ha salido un plan mejor?

Jugarme por una promesa, ser leal a una persona o a unos principios, estar en las buenas y en las malas, supone un temple especial, aquel que lleva a honrar la palabra empeñada. Tomarse en serio la promesa es estar dispuesto a quemar las naves para dedicarse ardientemente al proyecto de vida escogido, sin lancha aguardando a la orilla por si en el camino nos desanimamos. No hay vuelta, para disfrutar de la fragancia de la vida lograda, habrá que pasar por las penalidades del soldado. 
Para fortalecer la capacidad de prometer se requiere de una pedagogía de la promesa, que vuelva a valorar la conveniencia del esfuerzo en la actividad educativa. En términos teóricos, la pedagogía de la promesa está íntimamente unida al crecimiento de la virtud de la fortaleza, ella capacita para tener el arrojo suficiente a fin de asumir compromisos; asimismo, dota de la resistencia necesaria para sostener la promesa en el tiempo. Como se ve, la promesa requiere lealtad, fidelidad. Gabriel Marcel lo ha visto con mucha claridad y su indagación es certera. Dice que la fidelidad requiere de constancia y presencia (2004, pp. 158-184). La constancia es la repetición del acto, es perseverancia en el tiempo. La presencia, en cambio, es la luminosidad que mantiene vivo el espíritu de la promesa. Es cantar todos los días como si fuera ese el primer canto, celebrar los amaneceres como si fuera el primer amanecer, renovar el sí un día y otro.

\subsubsection{Elementos de la pedagogía de la promesa}

Corremos de un sitio para otro, nos afanamos en múltiples tareas. Tantas veces lo que nos queda de tiempo es tan solo para reponernos y vuelta a correr. Somos grandes consumidores de lo que se nos ponga por delante. Usamos y descartamos. Compramos enlatados. Un click y ya está caliente el refrigerio. Privilegiamos la velocidad y medimos al trabajador por sus resultados medidos con indicadores cada vez más eficaces. La escena famosa de Chaplin en Tiempos Modernos (1936), enloquecido por el trabajo trepidante y monótono de la fábrica, sigue siendo una realidad en tantos centros laborales: solo se han refinado los métodos.

Byung-Chul Han es un filósofo y ensayista coreano, capaz de escribir sobre aquellos asuntos que tantos pasamos de largo. Él sabe detenerse y lo obvio se convierte en destellos de buena sabiduría. Su libro El aroma 
del tiempo (2015) es una buena apología de lo que venimos diciendo: sin tiempo interior, sin capacidad para detenerse y trascender el instante, no es posible la promesa.

Dice Han que "las prisas, el ajetreo, la inquietud, los nervios y una angustia difusa caracterizan la vida actual. En vez de pasear tranquilamente, la gente se apremia de un acontecimiento a otro, de una información a otra, de una imagen a otra" (2015, p. 53). Pareciera que hemos desterrado de nuestro horizonte vital lo durable, lo que perdura, la capacidad de detenernos, de escuchar sin tener que mirar el reloj o el celular. En un ambiente así, "la promesa, la fidelidad o el compromiso, todas ellas prácticas temporales que crean un lazo con el futuro" (2015, p. 37) y delimitan el horizonte, pierden sustancia y se convierten en pompas de jabón.

Gracias a que corremos llegamos a tantas cosas positivas, no hay lugar a dudas. Pero, también está el riesgo de perdernos de tantas otras esferas de la vida personal que requieren, precisamente, que nos detengamos. Por ejemplo, disfrutar de la belleza. "Lo bello — dice Han — no es el resplandor o la atracción fugaz, sino una persistencia, una fosforescencia de las cosas (...) Solo cuando uno se detiene a contemplar, las cosas revelan su belleza, su esencia aromática” (2015, p. 75). Tiempo, por tanto, no para hacer más cosas, sino para estar en las importantes. Tiempo para conversar de esos asuntos que solo se hablan cara a cara y sin prisa. Tiempo para crecer.

La promesa requiere de libertad. Un primer momento es la libertad de coacción, es decir, libres de presiones que impidan el ejercicio de las decisiones humanas. Este primer momento se quedaría trunco sin el segundo momento, el de la libertad para. Una libertad sin vínculos es errática. Un hombre sin compromisos se pierde en el instante y en el capricho. La 
libertad, pues, en su sentido fuerte, dice Carlos Llano Cifuentes es "decidirse a, una decisión ejercida y no solo pensada” (1983, p. 29).

Desde esta perspectiva, una pedagogía de la promesa, debe enfatizar las actitudes humanas que hagan posible el compromiso de largo plazo e, incluso, el compromiso de toda la vida como es el proyecto matrimonial o el del celibato apostólico. Se trata de mostrar la hondura de estas dimensiones y, también, su belleza, de ahí que me refiera a ellas con la expresión elogio. Señalo cuáles son:
a) Elogio a la libertad
b) Elogio a la valentía
c) Elogio al esfuerzo
d) Elogio a la autoridad
e) Elogio al autocontrol
f) Elogio al sufrimiento

\section{Cultura de la Excelencia ${ }^{22}$}

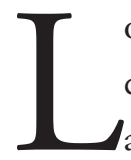

os años 90 del no muy lejano siglo XX fue una apoteosis de una cierta cultura del éxito. Se trataba de ser muy competitivo para llegar a ser el número uno. El liberalismo reinante de aquel entonces, sin un competidor tras la caída del Muro de Berlín en 1989, animaba a ese tipo de discurso triunfalista: si no eras un ganador, la vida no merecía la pena vivirse. Por lo menos, no podías pretender formar parte del club de los triunfadores.

22 Desarrollo varias de estas ideas de la cultura de la excelencia en Bobadilla (2015). 
Este esquema triunfalista de la vida volvía a revivir la teoría darwinista de la selección natural, esta vez en el campo social. La misma dinámica social introduciría una selección natural, de tal modo que los individuos más aptos conseguirían levantar la cabeza en esta lucha por la supervivencia. Desde esta perspectiva, no fueron pocos los planteamientos pedagógicos que se sumaron a este proyecto iluminista: se trataba de preparar a profesionales para el éxito en la vida y en los negocios. Ser el número uno, ser un ganador se convirtió en un objetivo existencial ${ }^{23}$.

Afortunadamente, la vida no es tan simple y basta una angina de pecho, un primer despido intempestivo o la quiebra de la empresa para darse cuenta que la biografía personal tiene también de heridas, fracasos y cicatrices; y que aquel grito de guerra "tú puedes", en ocasiones es, igualmente, un rotundo no puedo y no es el fin del mundo. Así lo ha visto, con especial clarividencia, Charles Handy cuando en La edad de la paradoja señala la necesidad de volver a definir qué es la supervivencia y la competencia, pues, si hemos de ir más allá de la supervivencia la pregunta es: ¿y ahora qué?:

Si lo tomamos en serio — dice Handy-, eso tiene visos de pesadilla, sin final y sin ganador. Solo una empresa puede ser el líder de un sector, solo un país puede estar en la cima económica; siempre hay vecinos más ricos o de más éxito con quienes compararnos. La competencia es saludable, tal vez incluso esencial, pero ha de haber algo más en la vida que ganar,

23 Véase Bruni (2018). Este autor, representante de la llamada economía civil, aboga por una economía que recupere la centralidad de la persona humana entre las cosas. Se mueve en la misma dirección de lo que planteamos en este ensayo: el éxito no es suficiente para alcanzar la plenitud de lo humano. Hace falta promover la dimensión efusiva o ética del don para llegar a la instancia plena del ser humano. 
de lo contrario prácticamente todos seríamos perdedores. (1996, p. 25)

Competir, ganar, tener éxito son momentos de la existencia humana, pero no lo es todo: hay más. La sola cultura del éxito es unilateral y tiende a formar caracteres intemperantes, personas ansiosas que han perdido la capacidad de esperar, que arrancan prematuramente el éxito a la vida. Son grandes emprendedores, pero vulnerables al fracaso. Velocistas de 100 metros planos, con los nervios de punta y músculos tensos. Buenos para el corto plazo, pero incapaces para las corridas de fondo; incompetentes para los proyectos de largo plazo y para los compromisos de toda la vida, en donde se juega el alma y la felicidad. Entonces, ¿qué? ¿O lo uno o lo otro? ¿O qué? Las dos cosas y más, es decir, la cultura de la excelencia para la vida buena.

Excelencia es el nombre con el que los griegos llamaban a las virtudes, esto es, aquellas cualidades humanas que despliegan la riqueza del ser humano. Una cultura de la excelencia, por tanto, lleva a un continuo afán de superación, articulando en la biografía humana logros y fracasos, alegrías y penas... Alejandro Llano en La vida lograda (2002) lo dice así:

La excelencia a la que aspiro no es la del completo acabamiento. Es seguir buscando lo bueno de la mejor manera que esté a mi alcance. Potenciar lo más posible mi ser práctico, para que mi capacidad operativa crezca acumulativamente. Una concepción estática y terminal de mi excelencia la convertiría en algo odioso para los demás e incluso para mí mismo. Para los demás sería la mayor falta de modestia, ya que aspiraría a presentarme como 
un modelo. Para mí supondría abocarme a la desesperanza, al proponerme algo inalcanzable. Paradójicamente, la excelencia excluye el perfeccionamiento total. (p. 141)

De esta cultura del éxito hay que rescatar el afán de logro, importante para conseguir resultados, más no puede estar basada solo en el cultivo de las competencias operativas y productivas. El éxito no es ajeno a la cultura de la excelencia, es uno de sus elementos, pero no el único, ni el más importante. El éxito, en este nuevo contexto vital, es una manifestación de la virtud de la fortaleza. Es la coronación del esfuerzo emprendedor que, con iniciativa, creatividad y disciplina, consigue la meta planteada. De este modo, el afán de logro sigue siendo un motor para grandes empresas, articulándose a otras finalidades de la vida que, igualmente, se alcanzan trabajosamente. Cultivar la inteligencia, fortalecer la voluntad, practicar las virtudes, abrirse al amor son tareas para toda la vida y desbordan el esquema ganar/perder: eficacia, por supuesto, pero en el seno de una vida lograda y fecunda. Este es el horizonte multicolor al que se abre quien se empeña en el ideal de la excelencia humana.

Vivimos en una cultura que enfatiza el éxito entendido como logros en el bienestar profesional, material, económico de la persona. Se favorece los resultados, los logros, los triunfos. Es una cultura centrada en el tener, reducido a tenencia posesiva material. Tiene mucho de altanería intelectual. El afán de logro se torna obsesivo. Genera ansiedad y una tendencia a cosechar frutos antes de tiempo o prematuramente. La respuesta a la hiperinflación de la cultura del éxito es la cultura de la excelencia, abarcadora del éxito y, también, integradora de los claroscuros de la biografía humana. 
Esta cultura de la excelencia requiere de una pedagogía del empoderamiento y de una pedagogía del don. Paso a explicarlas en el siguiente apartado.

\subsection{Pedagogía del empoderamiento}

La pedagogía del empoderamiento lleva al crecimiento de las dimensiones esenciales de la persona: inteligencia, voluntad y afectividad. En gran parte es la tradición pedagógica de la cultura clásica, magistralmente expuesta por Aristóteles y continuada — teórica y vitalmente- a lo largo de los siglos de la civilización occidental. En términos prácticos, la pedagogía del empoderamiento es la enseñanza de las virtudes cardinales. Enseñanza en las aulas y en las diversas comunidades de práctica que se generan al interior de los centros educativos y de las familias que componen el colegio.

\subsubsection{Las virtudes del encumbramiento de lo humano ${ }^{24}$}

A partir de este principio personalista de la buena sociedad, sigue el aprendizaje de lo que los clásicos griegos y latinos han llamado las virtudes cardinales, excelencias éticas que moderan y potencian hacia fines humanos las tendencias de los individuos. Allí deben estar la templanza, la fortaleza, la justicia y la prudencia. El esquema clásico de las virtudes compagina muy bien con un enfoque humanista orientado a la consecución de la sociedad buena. Las virtudes cardinales modulan las apetencias del ser humano. Todas ellas se miran y complementan entre sí.

24 Las ideas de empoderamiento (afán de logro) y don (efusión) se inspiran en los trabajos del profesor Carlos Llano. Son ideas transversales a muchos de sus escritos vinculados a las organizaciones. Entre ellos destacamos Llanos (2000) y (2004). 
- Templanza: Son necesarias personas templadas que no se queden enfangadas en los placeres desmedidos, vividores de lo inmediato, sin futuro, sin metas de largo plazo, expertas en oportunismo. La mujer y el hombre templados son señores de sí mismos, capaces de discernir el buen oro de la bagatela. Daniel Goleman se ha referido a esta competencia ética llamándola autocontrol y centra en ella la piedra angular de toda la inteligencia emocional.

- Fortaleza: La fortaleza también es necesaria, tanto para resistir y perseverar ante el bien arduo y difícil, como para emprender y acometer nuevas empresas. El fuerte no es quien no tiene miedo o sea impasible ante los obstáculos, no; el fuerte sabe esperar en su puesto, da la cara y se comporta con entereza ante las metas que solo se consiguen en el largo plazo, coloca la primera piedra con entusiasmo como todo buen emprendedor. También sabe colocar la última piedra, aun cuando el entusiasmo inicial ya no exista. Los obstáculos no lo frenan con facilidad. En su camino encontrará montes que ocultan el sendero. Puede vacilar, desorientado porque se le oculta la meta. Su capacidad de resistencia le hace continuar en la ruta. Al cabo de un tiempo vuelve a ver el camino. El esfuerzo valió la pena.

- Justicia: Nuestra sociedad requiere ciudadanos justos con el ánimo y voluntad dispuestas a darle a cada cual lo suyo, que no ignoren los logros de otros ni se adornen con los méritos de sus subordinados. Basta mirar la arbitrariedad que campea en tantos ambientes laborales, para darnos cuenta de la importancia de las personas justas. Porque de eso se trata: son justas o injustas las personas, no los procesos. El mejor sistema de control y de atribuciones puede 
resultar ineficaz si quien lo opera no es justo. Cuando falta la virtud personal de la justicia, ceder a la tentación del poder y del dinero es muy fácil. Quizás por eso, hasta ahora no podamos emprender una eficaz reforma judicial, puesto que centramos demasiado las esperanzas en los sistemas y nos olvidamos que la batalla crucial se libra en los corazones de los jueces.

- Prudencia: Quien pudiera, finalmente, saber vivir, acertar en las decisiones grandes y pequeñas de la vida, es la virtud de la prudencia, aquella recta razón en el obrar de la que hablaban los clásicos. Es la rectora de las virtudes y su acto propio es la decisión que lleva a actuar correctamente, en ese intento de los seres humanos de acertar y conseguir una vida lograda, con claroscuros, pero llena de sentido. Es la virtud del hombre y de la mujer de gobierno, ya en el hogar, en la empresa, en el centro educativo o en el Estado.

\subsection{Pedagogía del don}

La cultura nacional, al igual que gran parte de la cultura occidental de la que se nutre, está secularizada. La tentación para el educador bien intencionado es convertir el mensaje cristiano en una prédica —no del todo consciente- de Aristóteles y la paideia griega. Esto es mucho, desde luego, pero insuficiente para generar la locura de la entrega. Con el ideal de excelencia griega y cierto humanismo cívico conseguimos una sociedad pacífica, e incluso emprendedora. Hemos rescatado los mejores valores de la cultura burguesa: se hacen cosas, se evita el mal, pero no se hace el bien en grande. Eficacia, toda; generosidad y magnanimidad, escasa.

Las virtudes del encumbramiento o del emprendedor no son suficientes para conseguir la madurez y plenitud del ser humano. El acento 
está en el hacer, no en el dar. El emprendedor de éxito es típico de una cultura liberal, es el triunfo de la mentalidad calvinista. Es el homo faber en su mejor presentación. Una buena sociedad de raigambre católica no queda satisfecha formando buenos emprendedores. Su meta no se agota en evitar el mal, aspira a realizar el bien y llegar a la locura del amor que da la vida por el amigo. La cultura del éxito, buena en tantas cosas, se queda corta. Le sobra medida, cálculo y moderación. Hay, sin embargo, mezquindad de espíritu, demasiada razón utilitarista y, una vez más, no hay espacio para la locura cristiana.

El empoderamiento humano se queda corto si solo desarrolla las virtudes cardinales. La plenitud del ser humano pide más. El ser humano no es una mónada clausurada en sí misma. El ser humano, dice Pascal, supera al ser humano y solo encuentra su plenitud en la efusión y el don. Esto último supone comprender que todo lo que tenemos y somos no se clausura en una actitud de avaricia que atesora para sí mismo. Estamos llamados a la apertura, a poner al servicio del prójimo los talentos recibidos.

Hay muy buenas instituciones cuyo proyecto educativo busca acrecentar el talento de sus alumnos llevándolos al encumbramiento de sus capacidades intelectuales y virtuosas, en la dirección señalada por lo que hemos llamado pedagogía del empoderamiento. Encumbramos gran parte de las mejores fibras de lo humano, pero no llegamos a completar el cuadro de una antropología humanista y cristiana que llegue hasta la renuncia de sí. Como dice Chesterton, enseñamos a los alumnos a enriquecerse (en el más noble sentido de la palabra), pero no llegamos a enseñarles a empobrecerse (entregarse, ponerse al servicio de los otros con todo). La ética del emprendimiento sale bastante bien, falta dar el paso siguiente: la ética del desprendimiento o del don. 
La efusión, el desprendimiento, la entrega, el servicio tiene su propia pedagogía. Y si de virtudes se trata, hemos de fomentar la generosidad, la magnanimidad, la liberalidad, la humildad ${ }^{25}$. Todas ellas ingredientes de la caridad cristiana. Nuestra tarea es formar a nuestros alumnos en esta renovada cultura de la excelencia solidaria que los ilusione con la generación de proyectos grandes: cristianizar la sociedad, dar alegría a los demás, vivificar con el espíritu cristiano las entrañas del mundo. Ser conquistadores sin ambiciones; desprendidos, pero no pródigos ni dilapidadores.

\subsubsection{Virtudes de la pedagogía del don}

- Magnanimidad: Sin magnanimidad no hay líder que sea capaz de emprender algo y terminarlo. Magnánimo es el que se excede en el servicio: el aporte es mucho mayor a lo que se recibe. Con cálculo y cicatería no se va ni a la esquina. Calculador es aquel que, para hacer algo con otros, espera que los otros cumplan con su parte. Si los demás no dan lo suyo, el calculador no da un paso más. El magnánimo no se para ante esos cálculos, su generosidad es desbordante: piensa en grande y se da en grande, sin medida ni tacañería. ¡Cuántos proyectos se quedan en nada, porque sobró el cálculo y faltó la magnanimidad de unos pocos o, incluso solo de uno!

- Amistad: Siendo, además, la escuela una comunidad de vida relacional, se ha de vivir la experiencia de la amistad, sabiendo que no toda diferencia intelectual o de carácter es necesariamente enemistad o lucha bélica. Hemos de aprender a dialogar, buscando lugares de encuentro, afirmando coincidencias y haciendo valer

25 Carlos Llano (2004) habla de liderazgo humilde. 
pacíficamente las propias discrepancias. Homo homini naturaliter amicus decía Tomás de Aquino y no les faltaba razón. A pesar de las debilidades de los seres humanos, pesa más la amistad que la soledad y el interés. Cada persona es digna de ser amada, reduciríamos su calidad personal si solo viéramos en nuestro prójimo un escalón para subir o un simple medio para conseguir fines subalternos. Ser amigo es mucho más que trabajar en equipo, mucho más que saber organizar el aporte de los que trabajan conmigo. La amistad, siendo como es uno de los rostros más nobles del amor humano, abre cauces a las manifestaciones más propiamente humanas. Cuando hay amistad, la sola autoridad tiene mucha más capacidad de convocatoria que el poder o el miedo, por eso el líder ve en sus compañeros amigos y no piezas de ajedrez. Prefiere ir junto con los suyos — aunque más lentamente—, que llegar solo a la meta.

- Humildad: La persona íntegra no es un superhombre o una supermujer. No es un Dios del Olimpo, ni profeta, ni hijo de profetas. Está expuesto a las mismas tentaciones de cualquier ser humano, más aún, sabe de su fragilidad. Diría más, en su sencillez y transparencia, está su fortaleza. Sabe pedir perdón, es el primero en el servicio, no es altanero, ni oculta sus debilidades. Lejos de él la actitud de suficiencia, sabe escuchar, sigue aprendiendo. Después de un error no le sobreviene el derrumbamiento, sino la conciencia humilde de que su fortaleza es prestada al tú humano y al TÚ divino.

- Caridad: Amor a Dios y, por Él, amor al prójimo. Es la voluntad orientada al Tú divino y humano orientada a la afirmación de la persona en un despliegue intenso de efusión buscando satisfacer 
a necesidades materiales, cognitivas y afectivas de la persona. El ser humano se nos hace cercano y se constituye en prójimo, de tal manera que se nos hace cercano en sus necesidades de una manera afectiva y efectiva.

Desde luego, el elenco de las virtudes o cualidades personales es más extenso y variopinto. Aquí está el reto que nos presenta nuestro tiempo: ceder a la tentación tecnocrática y quedarnos contentos con los resultados numéricos de la operación o embarcarnos en la complejidad de la formación integral de nuestra gente. Lo primero no es sino un tributo a la eficacia, lo segundo es muestra de fecundidad.

Hasta que no nos vemos en la mirada del otro y, de lejano se convierte en cercano, no acabamos de comprendernos como seres humanos. La cultura de la excelencia reclama una cultura del don, en tanto es despliegue de la capacidad efusiva del ser humano o capacidad extática de la persona. El camino de la efusión lleva a comprender que solo se crece éticamente haciendo crecer al prójimo. Podemos hablar de una pedagogía del don, pedagogía del servicio, pedagogía de la entrega, pedagogía de la efusión. Todas estas expresiones hablan de la superabundancia del ser personal que, en términos prácticos, bien se pueden reflejar en las virtudes de la expansión de lo humano:

\subsection{Comunidades de práctica ${ }^{26}$}

Heroísmo, entrega, donación, ¿cómo fomentarlo? Es un trabajo conjunto de pensamiento y acción. Una formación que va desde lecturas

26 Desarrollo con más detenimiento el concepto de comunidades de práctica en Bobadilla (2002, pp.82-94). 
ejemplares haciendo notar el heroísmo de las gestas hasta acciones concretas de labor social: catequesis, visitas a los pobres, campamentos de trabajo, actividades de voluntariado. La formación humanística tiene un papel crucial en este tema, porque se trata de mostrarles a los alumnos todo el ser humano. Se trata de mostrar cómo el ser humano supera al ser humano.

El aprendizaje de la ética no se hace en las aulas, sino en comunidades de práctica. Con la conducta ética sucede lo que pasa con los artesanos: el aprendiz de zapatero aprende de un maestro zapatero. Este va introduciendo poco a poco en las prácticas de esa profesión al aprendiz. Este mira, recibe, repite las prácticas de su maestro. Pasado el tiempo, el aprendiz llegará a ser un experto con sus propias experiencias y estilo personal.

El aprendizaje ético sigue este camino. El ejemplo enseña. Quien desee saber cómo ser prudente, o cómo ser sobrio en las bebidas, ha de mirar e imitar al prudente y al templado, de ahí que resulte evidente que la familia es la comunidad de práctica por excelencia para lograr y crecer en cualidades éticas. Si no hay buenos maestros que enseñen con su vida las excelencias éticas, no hay aprendizaje ético que resista. Sin prácticas éticas es como pretender enseñar a nadar "en seco". Las clases teóricas de natación no son suficientes, ni siquiera es lo más importante. Para nadar hay que entrar en el agua. Igual con la ética, si la comunidad en la que se enseña, no práctica esas excelencias, el aprendizaje es nulo

El aprendizaje de las virtudes se hace en comunidades de práctica, llámese familia, colegio o empresa. El colegio es, junto con la familia, una auténtica comunidad de prácticas virtuosas (o de prácticas viciosas), para cuyo fin ha de alinear personas (directivos, profesores, personal operativo) y procesos (las paredes, los pisos, los sistemas de los colegios enseñan) a esta gran finalidad de aprendizaje: que los miembros del colegio encuentren 
en su institución ejemplos de conductas íntegras, no porque los profesores sean un dechado inmaculado de virtudes, sino porque muestran conductas comprometidas con la excelencia, aun cuando haya defecciones y quiebres.

Hemos de generar espacios para el encuentro, porque lo que convierte son corazones convertidos. Mientras más ámbitos que cultiven intereses de los alumnos y profesores, mejor. Es en las pequeñas comunidades de práctica en donde se llega a la formación personalizada y es allí donde cala a fondo la formación. Estoy pensando en los espacios para el coro, el deporte, el teatro, los círculos de lectura, los trabajos de investigación, etc. A estas actividades las llamamos extracurriculares. Término equívoco. Son verdaderas actividades formativas de igual categoría que una asignatura cognitiva. Estamos formando el carácter del chico o de la chica, no solo su cabeza.

\section{REFERENCIAS}

Barron, R. (2017). Catolicismo. Un viaje al corazón de la fe. Madrid, España: Rialp.

Barron, R. (2018). Encender fuego en la tierra. Anunciar el Evangelio en un mundo secularizado. Conversaciones con John L. Allen. Madrid, España: Palabra.

Benedicto XVI. (2008). Mensaje a la Curia Roma, 22. XII. 08. Recuperado de http://www.vatican.va/content/benedict-xvi/es/speeches/2008/ 
december/documents/hf_ben-xvi_spe_20081222_curia-romana. html

Bobadilla, F. (2002). Empresas con alma. Piura, Perú: Ediciones Universidad de Piura.

Bobadilla, F. (2010). Poesía y antropología en Tríptico Romano. En V. Velezmoro (ed.). Duc in altum. Estudios preliminares sobre la figura y el pensamiento de Juan Pablo II (pp. 59-72). Piura, Perú: Ediciones Universidad de Piura.

Bobadilla, F. (2014). El emotivismo libertario y sus secuelas. Studium Veritatis, 12(18), 127-150. Recuperado de https://studium.ucss. edu.pe/index.php/SV/article/view/43/293

Bobadilla, F. (2015). Pasión por la excelencia (3. ${ }^{a}$ ed.). Lima, Perú: Acres.

Bruni, L. (2018). Virtudes y vicios del mercado. Palabras para una economía humana. Madrid, Ciudad Nueva.

Buber, M. (1998). Yo y Tú (Trad. C. Díaz). Madrid, España: Caparrós Editores.

Buber, M. (1997). Diálogo. Diálogo y otros escritos (Trad. C. Moreno). Barcelona, España: Riopiedras.

Chesterton, G. K. (2012). El acusado. Salamanca, España: Ediciones Espuela de Plata.

Francisco. (2018). Dios es joven. Lima, Perú: Editorial Planeta Perú.

Frankl, V. (2015). El hombre en busca del sentido (3. ${ }^{a}$ ed.). Barcelona, España: Herder.

García Hoz, V. (1962). Cuestiones de filosofía individual y social de la

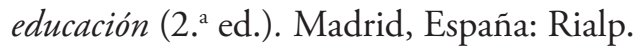


García Hoz, V. (1987). Pedagogía visible y educación invisible. Madrid, España: Ediciones Rialp.

González Umeres, L. (dir.). (2009). La integración de los saberes. Un reto para la filosofía de nuestro tiempo. Piura, Perú: Ediciones Universidad de Piura.

Grondin, J. (2014). A la escucha del sentido. Conversaciones con Marc-Antoine Vallée. Barcelona, España: Herder.

Han, B-Ch. (2015). El aroma del tiempo. Barcelona, España: Herder.

Han, B-Ch. (2016). La salvación de lo bello. Barcelona, España: Herder.

Handy, Ch. (1996). La edad de la paradoja. Dar sentido al futuro. Barcelona, España: Ediciones Apóstrofe.

Lipovetsky, G. (2008). La sociedad de la decepción. Barcelona, España: Anagrama.

López Quintás, A. (1999). Inteligencia creativa. El descubrimiento personal de los valores. Madrid, Espańa: Biblioteca de Autores Cristianos.

Llano, A. (2002). La vida lograda. Barcelona, España: Ariel.

Llano, A. (2004). Humildad y liderazgo. México D.F., México: Ediciones Ruz.

Llano Cifuentes, C. (1983). Las formas actuales de la libertad. México. México: Editorial Trillas.

Llano Cifuentes, C. (2000). La amistad en la empresa. México D.F., México: Fondo de Cultura Económica.

Marcel, G. (2004). De la negación a la invocación. Cap. VIII, La fidelidad creadora. Obras selectas, II (pp. 158-184). Madrid, España: Biblioteca de Autores Cristianos. 
Moeller, Ch. (2008). Sabiduría griega y paradoja cristiana. Madrid, España: Ediciones Encuentro.

Polo, L. (1995). Introducción a la filosofía. Pamplona, España: EUNSA.

Polo, L. (1996). La Verdad como inspiración. La persona bumana y su crecimiento (pp. 197-206). Pamplona, España: EUNSA.

Polo, L. (2006). Ayudar a crecer. Cuestiones filosóficas de la educación. Pamplona, España: EUNSA.

Sánchez, G. (2018). El Papa Francisco y la cultura del encuentro. Aspectos teológicos de una enseñanza central. Teología y sociedad. Reflexiones a la luz del pensamiento del Papa Francisco. Lima, Perú: Ediciones Facultad de Teología Pontificia y Civil de Lima.

Sarah, R. (2016). La fuerza del silencio. Madrid, España: Palabra.

Sennet, R. (2000). La corrosión del carácter. Las consecuencias del trabajo en el nuevo capitalismo (3. ${ }^{a}$ ed.). Barcelona, España: Anagrama.

Solzhenitsyn, A. (1978). Alerta a Occidente. Barcelona, España: Adiciones Acervo.

Vargas Llosa, M. (2012). La civilización del espectáculo. Lima, Perú: Alfaguara. 